\title{
LUCRO INFLACIONÁRIO: UMA REPOSTA OBJETIVA
}

\author{
Ariovaldo dos Santos \\ Professor Doutor da FEA/USP \\ Pesquisador da FIPECAFI
}

A Revista Brasileira de Contabilidade no. 95, de setembro/outubro de 1995, trouxe matéria assinada por Antonio Lopes de Sá intitulada "Razões Conceituais sobre a Falsidade do Lucro Inflacionário", em que o professor, mais uma vez, vem á público para divulgar suas lições a respeito desse assunto. $O$ autor cita textualmente que, para elaboração do artigo, baseou-se em bibliografia composta de 107 títulos (livros, artigos, normas, etc) e coloca a relação à disposição dos interessados.

Dentro do mais alto espírito acadêmico da pesquisa sobre o que é mais correto, e com todo o respeito merecido, queremos afirmar que, aquele autor, a nosso ver não foi feliz em determinados aspectos conceituais e técnicos.

Poderíamos dividir nossas críticas em duas partes: listar, na primeira, uma série do que consideramos equívocos conceituais e, na segunda, detalhar os outros que são apresentados no exemplo numérico. As críticas relativas à primeira parte já foram apresentadas em diversas matérias publicadas anteriormente por órgãos de divulgação, inclusive na própria Revista Brasileira de Contabilidade.

Para evitarmos a leitura repetitiva e citações de autores renomados, nascidos neste século ou em séculos anteriores, mas que não viveram ou estudaram nossa realidade inflacionária, vamos nos concentrar no exemplo numérico do referido artigo.

\section{O EXEMPLO APRESENTADO}

Em apêndice apresentado sob o título "Lucro Inflacionário com Perda Patrimonial", o professor diz, textualmente, o seguinte:

"O sistema, de fato, mascara a realidade, mascara as perdas e cria perdas em quem de fato não as suporta".

O trabalho, do exemplificado, é de autoria do professor Giovanni Coridola, controlador e contador de uma das maiores empresas do seu ramo, no País.

Caderno de Estudos nº13, São Paulo, FIPECAFI - Janeiro a Junho/1996 
O exemplo é extremamente didático e ressalta toda a fantasia das correções, pois parte de uma empresa em movimento, durante certo tempo, portanto sem qualquer interferência de dinheiro, quer entrado, quer "saído".

Como se pode depreender do texto reproduzido, o exemplo utilizado foi elaborado por alguém da confiança do professor Antonio Lopes de Sá e que merece dele todo o respeito técnico. Por razões estritamente didáticas, vamos representá-lo.

\begin{tabular}{|l|l|l|l|}
\hline \multicolumn{3}{|c|}{ MOMENTO 1 } \\
\hline Ativo Circulante & $\$ 100$ & Exigibilidades & $\$ 300$ \\
\hline Ativo Permanente & $\$ 400$ & Patrimônio Líquido & $\$ 200$ \\
\hline
\end{tabular}

\begin{tabular}{|c|c|c|c|}
\hline \multicolumn{4}{|c|}{ MOMENTO 2} \\
\hline Ativo Circulante & $\$ 100$ & Exigibilidades & $\$ 600$ \\
\hline Ativo Permanente & $\$ 800$ & Patrimônio Líquido & $\$ 300$ \\
\hline Anterior & & Corrigido & \\
\hline Correção & & Perdas & \\
\hline
\end{tabular}

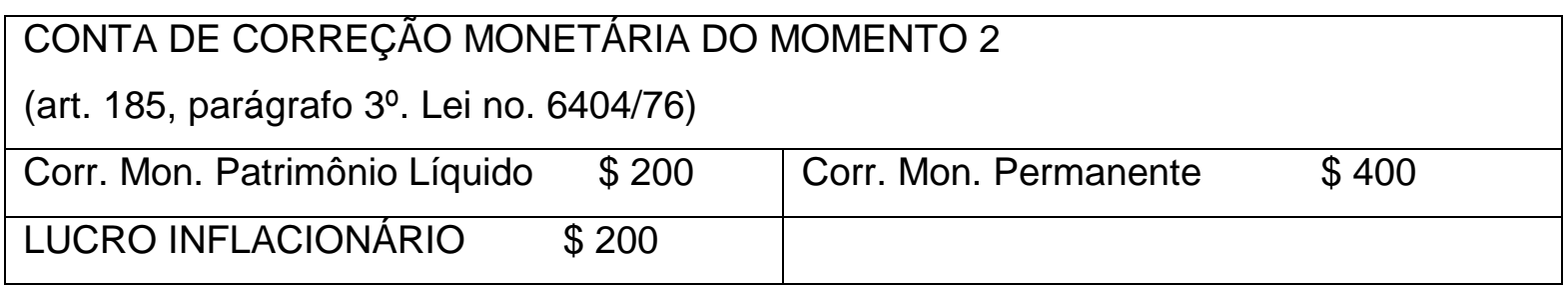

\begin{tabular}{|c|c|c|c|}
\hline \multicolumn{4}{|c|}{ CONTA DE RESULTADOS DO MOMENTO 2} \\
\hline Custo Fianceiro & $\$ 300$ & LUCRO INFLACIONÁRIC & 200 \\
\hline & & Perda Aritmética & $\$ 100$ \\
\hline
\end{tabular}

Perda Figurada em Balanço $\$ 100$

Perda Real $\$ \underline{\$ 300}$

Caderno de Estudos nº13, São Paulo, FIPECAFI - Janeiro a Junho/1996 


\begin{tabular}{|lcc|lcc|}
\hline Ativo Circulante & & $\$ 100$ & Exigibilidades & & $\$ 1.200$ \\
\hline Ativo Permanente & & $\$ 1.600$ & Patrimônio Líquido & & $\$ 500$ \\
\hline Anterior & $\$ 800$ & & Corrigido & $\$ 300$ & \\
\hline Correção & $\$ 800$ & & Perdas & $\$ 100$ & \\
\hline
\end{tabular}

$\left({ }^{*}\right)$ observemos que, na elaboração do exemplo, aparentemente, deve ter havido um erro no momento da impressão. O número correto, imaginamos ter sido a intenção dos autores, é de $\$ 600$, isto é, o valor do Patrimônio Líquido anterior de \$ 300 devidamente atualizado pela inflação de $100 \%$. Disto resultaria um valor corrigido de $\$ 600$ que, após a redução das perdas de \$100, totalizaria \$500, valor apresentado no Patrimônio Líquido no Momento 3.

\begin{tabular}{|lc|ll|}
\hline \multicolumn{4}{|l|}{ CONTA DE CORREÇÃO MONETÁRIA DO MOMENTO 3 } \\
\hline Corr. Mon. Patrimônio Líquido & $\$ 300$ & Corr. Mon. Permanente & $\$ 800$ \\
\hline Lucro Inflacionário & $\$ 500$ & & \\
\hline
\end{tabular}

\begin{tabular}{|lc|lc|}
\hline \multicolumn{4}{|l|}{ CONTA DE RESULTADOS DO MOMENTO 3 } \\
\hline Custo Financeiro & $\$ 600$ & Lucro Inflacionário & $\$ 500$ \\
\hline & & Perda Aritmética & $\$ 100$ \\
\hline
\end{tabular}

$\begin{array}{lr}\text { Perda Figurada em Balanço } & \$ 100 \\ \text { Perda Real (Custo) } & \$ 600 \\ \text { Lucro Inflacionário } & \$ 500\end{array}$

Mais uma vez, vamos reapresentar o exemplo utilizado pelo ilustre professor, fazendo algumas poucas adaptações de forma.

\begin{tabular}{|l|l|l|l|}
\hline \multicolumn{4}{|c|}{ BALANÇOS PATRIMONIAIS (\$) } \\
\hline Ativo & Momento 1 & Momento 2 & Momento 3 \\
\hline Circulante & 100 & 100 & 100 \\
\hline
\end{tabular}

Caderno de Estudos nº13, São Paulo, FIPECAFI - Janeiro a Junho/1996 


\begin{tabular}{|c|c|c|c|}
\hline Permanente & 400 & 800 & 1.600 \\
\hline Total do Ativo & 500 & 900 & 1.700 \\
\hline \multicolumn{4}{|l|}{ Passivo+PL } \\
\hline Exigibilidades & 300 & 600 & 1.200 \\
\hline Patrimônio Líquido & 200 & 300 & 500 \\
\hline $\begin{array}{ll}\text { Inicial } & 200\end{array}$ & 400 & 800 & \\
\hline $\begin{array}{l}\text { Resultados } \\
\text { Acumulados } 0\end{array}$ & $(100)$ & $(300)$ & \\
\hline Total do Passivo+PL & 500 & 900 & 1.700 \\
\hline
\end{tabular}

\begin{tabular}{|c|c|c|c|}
\hline \multicolumn{4}{|c|}{ DEMONSTRAÇÕES DE RESULTADOS (\$) } \\
\hline Contas & Momento 2 & Momento 3 & Acumulado \\
\hline $\begin{array}{ll}\text { Despesas } & \text { Financeiras } \\
\text { Nominais } & \end{array}$ & $(300)$ & $(600)$ & $(900)$ \\
\hline Correção Monetária & 200 & 500 & 600 \\
\hline Permanente 400 & 800 & 1.200 & \\
\hline PL. Inicial $\quad(200)$ & $(400)$ & $(600)$ & \\
\hline Resultado Acumulado d & 100 & 0 & \\
\hline Resultado Líquido & $(100)$ & $(100)$ & $(300)$ \\
\hline
\end{tabular}

Podemos perceber, através dos dados apresentados no exemplo elaborado pelo professor Giovanni e assumidos pelo professor Antonio Lopes de Sá, que os níveis de inflação considerados foram de $100 \%$ ao ano. As atualizações das contas de Ativo Permanente e Patrimônio Líquido foram efetuadas por esses índices, que também serviram de base para a atualização das dívidas, expressas no exemplo como Exigibilidades.

\section{A ANÁLISE PROPRIAMENTE DITA}

Para facilitar a compreensão dos leitores e para que não haja qualquer grau de dispersão no entendimento das questões colocadas, vamos reproduzir algumas das suas afirmações. Diz o professor:

"O exemplo mostra uma perda real de substância da empresa em 900 (crescimento de sua dívida de 300 para 1.200), que são efetivos custos financeiros computáveis, na realidade, quando iniciar as suas operações; mas em balanço, demonstrável para terceiros, as perdas

Caderno de Estudos nº13, São Paulo, FIPECAFI - Janeiro a Junho/1996 
evidenciadas foram apenas de 200, em razão da ficção de um Lucro Inflacionário de 700 (que nada acrescentou a um patrimônio que será usado para produzir)".

Quer nos parecer que esse raciocínio apresenta alguns equívocos. No exemplo demonstrado, podemos verificar que as dívidas da empresa, entre o momento 1 e o momento 3, foram “"'atualizadas"de $\$ 300$ para \$1.200. Essa atualização ocorreu por causa da inflação acumulada de $300 \%$ no período. Não podemos esquecer que $100 \%$ de inflação em dois períodos consecutivos totaliza, no período global, uma inflação de $300 \%$. Isso implica dizer que a dívida foi nominalmente multiplicada por 4, mas não significa que seja 4 vezes o que era; afinal em termos reais, a dívida é exatamente a mesma.

Dessa forma, chamar o crescimento da dívida, originado exclusivamente pela simples atualização monetária, de efetivos custos financeiros computáveis, nos parece, é esquecer o que significa um processo inflacionário. Em verdade, a dívida teve seu valor aumentado apenas nominalmente. Ou será que qualquer poupador brasileiro, após aplicar seu capital de $\$ 300$, num período de inflação de 300\% acreditará ter um "ganho" de $\$ 900$, apenas por ter $\$ 1.200$ no final? É muito claro que não. Esse poupador tem absoluta consciência que o "rendimento real", dessa modalidade de aplicação, no Brasil, é apenas o que excede a inflação (6\% a.a., na maior parte dos últimos anos). O resto (correção monetária, seguro contra inflação ou qualquer outra denominação) é mera recomposição do capital aplicado. Assim, é um grande engano denominar o acréscimo nominal da dívida de "efetivos custos financeiros".

Outra afirmação do ilustre professor:

"Na prática, a empresa pagará, ao banco ou a terceiros., mais 900 e precisará extrair de sua receita tal valor, para tanto imputando nos custos tal realidade (não só de caixa)".

Novamente, percebe-se que o raciocínio desenvolvido, não considera a experiência , infelizmente vivida pelo povo brasileiro, de convivência com a inflação.

Como já explicamos anteriormente, a dívida foi alterada apenas em seu valor nominal; em termos reais, as obrigações dessa empresa, pela ausência de taxa real de juros, permaneceram do mesmo tamanho.

Outra equivocada afirmação é apresentada a seguir:

"Nossa legislação fiscal fala em lucro inflacionário acumulado como 'soma do lucro inflacionário acumulado do período-base com o saldo do lucro inflacionário a tributar, transferido do ano-base anterior'(art.21, parágrafo $2^{\circ}$, Lei no. 7799/89)".

Para a lei fiscal, é lucro inflacionário o saldo credor da conta de correção monetária (art. 21 da mesma Lei no. 7799/89) de seus ajustes "monetários".

Caderno de Estudos nº13, São Paulo, FIPECAFI - Janeiro a Junho/1996 
À frente o professor complementa:

"Tanto é firme o conceito de lucro inflacionário como defluência da correção monetária, que é tributável, como se lucro fosse, embora lucro, em verdade, não exista".

Nessas afirmações há uma ampla confusão, fiscal e prática, apresentada no exemplo. Senão, vejamos.

A legislação fiscal empunhada para criticar a tributação de um lucro que não existe foi mal utilizada, uma vez que, no exemplo apresentado, não há "lucro inflacionário" fiscal.

A legislação define que o "lucro Inflacionário", como citado no parágrafo anterior, só ocorrerá se o saldo credor da conta de correção monetária for superior ao valor dos ajustes de variação monetária.

Dessa forma, no exemplo apresentado, não há a figura fiscal do "lucro inflacionário", visto que o saldo credor de correção monetária referidos. A legislação fiscal trata a atualização dos empréstimos como ajustes monetários e esses valores são superiores ao saldo credor da conta de correção monetária.

Outro equívoco, do ponto de vista prático, está na própria apresentação do exemplo pois, após as atualizações efetuadas, percebe-se que o resultado da empresa foi um prejuízo de $\$ 300$ e não de $\$ 200$ (veja transcrição dessa afirmação no início desta análise).

O que efetivamente aconteceu? A resposta é muito simples. O Patrimônio Líquido dessa empresa no Momento 1 era de $\$ 200$ e, para que tivesse o mesmo tamanho ao final do Momento 3, após 300\% de inflação, deveria totalizar \$800. Como o valor do Patrimônio Líquido ao final do período totalizava apenas $\$ 500$, pode-se concluir, sem qualquer tipo de sofisma, que o resultado foi negativo de $\$ 300$. Essa comparação direta pode ser feita sem nenhuma restrição, porque o exemplo não contempla aumentos de capital, constituições de reservas de capital, distribuição de resultados, etc.

O erro que podemos denunciar está no raciocínio utilizado para a acumulação do resultado. O professor, discorrendo sobre o exemplo preparado por terceiro, não atentou para o detalhe da atualização do resultado apurado no Momento 2. Se tomarmos o "resultado nominal"do Momento 2, que foi de \$100, e adicionarmos a ele o resultado do Momento 3, que também foi de $\$ 100$, realmente teremos um total de $\$ 200$. Ocorre que esta soma não pode ser feita de forma tão simples. É como se pudéssemos somar 100 dólares americanos com 100 dólares canadenses e afirmamos que o total é de 200 dólares neozelandeses. Claro que isso é absurdo!

Entre o Momento 2 e o Momento 3 tivemos 100\% de inflação, o que significa que o resultado de $\$ 100$ do Momento 2, em moeda do Momento 3, é de $\$ 200$. Esse valor, após 
as necessárias atualizações monetárias, adicionadas ao resultado de $\$ 100$ do Momento 3, totaliza um prejuízo de $\$ 300$ e não de $\$ 200$.

\section{A EXPLICAÇÃO FINAL}

O exemplo utilizado, naquele artigo citado, apresenta o Ativo Circulante pelo valor inicial de $\$ 100$ e admite que esse valor permanece imutável até o final do Momento 3. Como esse valor não foi especificado se era composto por ativos monetários (Caixa, Bancos, Clientes, etc.) ou ativos monetários (Estoques de Produtos, Matérias-Primas, Mercadorias, Despesas Antecipadas, etc.), vamos apresentar as explicações do que teria acontecido nas duas alternativas:

\section{1‥ ALTERNATIVA: ATIVO CIRCULANTE COMPOSTO POR ATIVO MONETÁRIO}

Como foi demonstrado, de forma inequívoca e insofismável, a empresa utilizada como exemplo apresentou um prejuízo de $\$ 300$. Demonstraremos, agora, onde é que realmente essa empresa perdeu.

A hipótese de que não houve qualquer movimentação de receitas e despesas nos permite um raciocínio bastante simples, porém absolutamente correto.

Se admitirmos que o Ativo Circulante é composto por Caixa, na verdade, a empresa terá tido sua perda realizada na péssima administração que fez com seu ativo monetário, que ficou exposto à inflação de todo o período sem qualquer tipo de atualização.

Em outras palavras, se o valor de $\$ 100$ existente no Caixa no Momento 1 tivesse sido aplicado no mercado financeiro, recuperando apenas a inflação do período, ao final do Momento 3 esse valor seria de \$400. Como essa aplicação não foi efetuada, a empresa apresenta um prejuízo que representa perda real de $\$ 300$.

Mesmo diante de todas essas evidências, o autor afirma textualmente:

"A singeleza do raciocínio (porque não entra detalhes, nem de juros sequer) evidencia o disparate de uma ficção que grava justamente as empresas que mais precisam capitalizar e crescer, na base do aproveitamento de suas capacidades produtivas".

"Empresas que precisem capitalizar e crescer, na base do aproveitamento de suas capacidades produtivas", não podem se dar ao luxo de manterem seus ativos monetários expostos à inflação sem qualquer tipo de remuneração nominal, que é pura proteção".

Caderno de Estudos nº13, São Paulo, FIPECAFI - Janeiro a Junho/1996 


\section{2a ALTERNATIVA: ATIVO CIRCULANTE COMPOSTO POR ATIVO NÃO MONETÁRIO}

Nesse caso, ao contrário do que defende o professor, condenado a existência da sistemática brasileira de correção monetária, o que se deveria fazer é estendê-la também aos Estoques ou a qualquer outro ativo não monetário (classificado fora do Ativo Permanente). Além do mais, nossa defesa da sistemática brasileira de correção monetária sempre foi condicionada a alguns ajustes e a correção monetária integral, que considera as correções de Estoques, ajuste a valor presente de clientes, etc.

Voltando ao exemplo, se os estoques fossem corrigidos de $\$ 100$ para $\$ 400$, esse acréscimo de $\$ 300$ acabaria por anular o resultado negativo de $\$ 300$. Aí, sim, teríamos a lógica de resultados pretendida pelo professor Antonio Lopes de Sá, se a empresa não operou durante o período e tem seus ativos e passivos compostos apenas por itens não monetários, o resultado do período teria que ser zero.

Então, poderíamos voltar à questão que o professor contesta: Por que corrigir? Simplesmente porque, se não o fizermos, nossos balanços e resultados, atuais e futuros, serão totalmente deturpados. Só para elucidar: o exemplo elaborado, no Momento 1, apresenta o valor do ativo Permanente como sendo de \$400. Se nenhuma atualização tivesse sido feita, como não houve aquisições, baixas e depreciações, o Ativo Permanente no momento 3 , também estaria apresentado com valor de $\$ 400$. Isso sim é que descaracterizaria totalmente nossos balanços. A atualização de \$ 400 para \$1.600 não significa que se esteja agregando valor ao ativo, pelo contrário, o que se está fazendo é manter as características originais de valor desse ativo.

Já pensaram o que seria dos Ativos Permanentes das empresas brasileiras, não fosse a sistemática de reconhecimento da inflação, estabelecida pela lei ? E, para não exagerar, o que seria dos valores dos ativos adquiridos na década de 90 e apresentados nos balanços de 1995? Será difícil entender isso? Temos certeza que não.

Imaginemos, ainda, no exemplo em questão, não se efetuar qualquer tipo de atualização monetária e, ao final do terceiro período, vender-se o imóvel por \$1.700. Teríamos, na ausência da correção monetária, um lucro contábil de $\$ 1.300$.

Que incoerência pagar imposto sobre esse falso lucro que, agora,sim, terceiros chamariam corretamente de "lucro mero contábil", porque não representa o efetivo ganho do capital. Afinal, esse ganho só existe se o ativo for vendido por valor superior ao do mero e simples efeito da inflação.

Caderno de Estudos nº13, São Paulo, FIPECAFI - Janeiro a Junho/1996 
É claro que existem outras formas possíveis de ajuste por efeito da variação de preços. O próprio professor Antonio Lopes de Sá tem falado, às vezes, no uso do custo de reposição como base de valor. Apesar de isso contrariar os atuais Princípios Fundamentais de Contabilidade, como admitimos ser esse outro princípio de avaliação muito discutido e, às vezes, até praticado nas demonstrações contábeis para fins externos (mesmo com freqüência raríssima, como em algumas empresas na Holanda).

Basta ver a maior obra já escrita até hoje sobre o assunto e a universalmente mais citada: EDWARS \& BELL - The Theory and Measurement of Bussiness Income; University of Califórnia Press, 1961, bem como em dezenas de outras, que também podemos referenciar. Nelas, vê-se que: um Ativo, como o Imobilizado, do nosso exemplo em questão, poderia ser substituído pelo valor de reposição do mercado, mas só seria considerado como efetiva e real variação de Patrimônio Líquido (computada no resultado, na opinião de alguns, ou diretamente como Reserva, na opinião de outros, como é o caso da reavaliação na Legislação Brasileira) o que fosse acréscimo de valor de mercado além do efeito inflacionário.

No nosso exemplo, se houvesse redução de valor, ou seja, se o valor de reposição fosse interior ao valor corrigido monetariamente de $\$ 1.600$, existiria o registro de uma perda.

Assim, vê-se que numa situação de inflação razoavelmente significativa, não há como fugir, primeiro, da aplicação da atualização monetária. Somente após isso, faria sentido substituir-se o valor atualizado pelo efetivo valor da reposição, com o cômputo da diferença como efetiva agregação ou perda de valor.

A "prova dos nove": se a inflação é mesmo de $300 \%{ }^{1}$ no período e se usássemos uma moeda forte, que chamaremos de UMC (Unidade Monetária Contábil), podendo ser a UFIR ou uma moeda estrangeira estável que também tivesse variado os mesmos $300 \% 1$, teríamos:

\begin{tabular}{|lc|lc|}
\hline \multicolumn{4}{|c|}{ MOMENTO 1 (1 UMC = \$ 1) } \\
\hline Ativo Circulante & 100 UMC & Exigibilidades & 300 UMC \\
\hline Ativo Permanente & 400 UMC & Patrimônio Líquido & 200 UMC \\
\hline & 500 UMC & & 500 UMC \\
\hline
\end{tabular}

\footnotetext{
${ }^{1}$ O Plano Real mostrou que usar moeda estrangeira não é uma boa forma de converter os balanços; o melhor é a nossa taxa interna de inflação mesmo, como afirmam a ONU e o IASC.
} 


\begin{tabular}{|c|c|c|}
\hline \multicolumn{3}{|l|}{ MOMENTO 3 ( 1 UMC = \$ 4) } \\
\hline$\$ 100: 4=25$ UMC & Exigibilidades & $\$ 1.200: 4=300$ UMC \\
\hline Ativo Permanente $\$ 1.600: 4=400$ UMC & Patrimônio Líquido & $\$ 500: 4=125$ UMC \\
\hline 425 UMC & & 425 UMC \\
\hline
\end{tabular}

Comparando-se os dois balanços, usando aqui a hipótese de Ativo Circulante composto apenas de itens monetários, o que vemos?

- O Ativo Circulante diminui 75 UMC;

- O Ativo Permanente continuou o mesmo;

- As Exigibilidades continuaram as mesmas.

Se o imobilizado continuou o mesmo, onde está o lucro inflacionário da correção do Ativo Permanente?

A inflação corroeu o poder de compra do Ativo Circulante e isso não é prejuízo? A empresa não tem menos recursos financeiros do que tinha?

Finalizando, queremos enfatizar, de forma veemente, que o professor Lopes de Sá, sempre trabalhou em prol da Contabilidade brasileira, assim como tantos outros pesquisadores deste País. Mas é interessante frisar que uma das maiores contribuições para o avanço da Contabilidade, a nível mundial, é exatamente a correção monetária societária (pela genialidade de sua simplicidade) e, particularmente, a correção monetária integral, pela universidade e qualidades gerenciais; correção integral essa que, em março de 1989, não só foi aceita como também foi recomendada pela ONU para o mundo inteiro. O IASC, que usa um modelo semelhante, entretanto mais simplificado, declarou (conforme o registro da ONU no ISAR/GROUP - 1989) que o modelo brasileiro era o mais avançado que se conhecia.

Estamos e estaremos sempre dispostos a discutir novos conceitos e formas diferentes de encarar, droutinariamente, a Contabilidade. Não nos consideramos como os únicos donos da verdade, mas não podemos, em nenhuma hipótese, deixar de nos pronunciar quando, a nosso ver, equívocos são cometidos, mesmo por pessoas tão eminentes que, certamente, entenderá ${ }^{2}$ esse artigo como consideramos o dele: contribuição à busca da verdade, com diferenças de pensamento, mas sem qualquer problema de relacionamento pessoal. 


\section{RESUMO}

Este trabalho procurou esclarecer algumas das dúvidas existentes quanto ao entendimento do real significado da forma brasileira de reconhecimento da inflação nas demonstrações contábeis.

Pela dificuldade de compreensão e aceitação demonstradas por alguns renomados autores, esse assunto tem provocado grandes polêmicas.

Das discussões, surgiram excelentes trabalhos, que foram, sem nenhuma dúvida, auxiliando a obtenção de melhores demonstrações contábeis. Aqui, fez-se uma análise crítica de uma dessas publicações.

\section{REFERÊNCIAS BIBLIOGRÁFICAS}

IUDíCIBUS, Sérgio de; MARTINS, Eliseu e GELBCKE, Ernesto Rubens - Manual de Contabilidade das Sociedades por Ações. 4ํㅜ ed., São Paulo: Atlas, 1995.

MARTINS, Eliseu - Aspectos do Lucro e da Alavancagem Financeira no Brasil. São Paulo, 1979. Tese de Livre-Docência, Faculdade de Economia, Administração e Contabilidade USP.

SANTOS, Ariovaldo dos - Alguns Efeitos da Utilização de índices inadequados na Correção dos Balanços das Empresas Estrangeiras no Brasil. São Paulo, 1993. Tese de Doutorado, Faculdade de Economia, Administração e Contabilidade - USP. 